\title{
[survey Report] How WiMAX will deploy in India
}

\author{
Rakesh Kumar Jha \\ Department of Electronics and \\ Communication Engineering \\ SVNIT,Surat \\ Gujarat, India 395007 \\ Email: jharakesh.45@gmail.com \\ https://sites.google.com/site/jharakeshnetworkcom/
}

\author{
Dr Upena D Dalal \\ Department of Electronics and \\ Communication Engineering \\ SVNIT,Surat \\ Gujarat, India 395007 \\ Email: upenadalal@yahoo.com \\ http://svnit.ac.in/
}

\begin{abstract}
How WiMAX can be deployed in India is really a challenge for researchers with respect to the country's structure prospective. WiMAX subscriber base is expected to reach 19 million by 2012 and WiMAX equipment market value to top US\$ 600 million. Eventually following the auction of $2.3 \mathrm{GHz}$ and 2.5GHz licenses in the first quarter of 2010, the Indian WiMAX market presents enormous business opportunities. This report seeks to provide a comprehensive picture of WiMAX development in India, focusing ion three aspects of policy, industry, and market. Topics include India's telecom and WiMAX spectrum licensing policies, as well as issues related to WiMAX equipment certification; profile of the overall WiMAX industry in India and current development of companies positioned throughout the industry value chain; an overall sketch of the WiMAX subscriber market in India and outline of Indian WiMAX carriers current status and future development.
\end{abstract}

\section{INTRODUCTION}

WiMAX, Worldwide Interoperability for Microwave Access, is an emerging wireless communication system that can provide broadband access with large-scale coverage. As a cost-effective solution, multi-hop communication is becoming more and more important to WiMAX systems. But there will be no benefit, if this research will not full fill the nation's requirement. Thus this paper gives a brief survey on WiMAX deployment for India's prospective and also gives some useful data in this way. This will provide interest to deploy the WiMAX in the country. India started its economic liberalization program in 1991. In 1994, the first step to opening the telecom market to privatization was taken. The first private sector wire line and cellular licenses were issued in 1995. From then on, Indian telecom has seen and crossed several milestones and many missteps that provided valuable lessons. The effective telecom tariff for domestic voice service has dropped from Rs 14 per minute (US\$ 0.3 at US\$1 $=$ Rs 44.5) to about Rs 1 (US\$ 0.02) per minute in the last 10 years. The result is that the number of telephone connections (wire line and wireless lines) has doubled in the past two years, to about 150 million. The Ministry of Telecom has set a target for 2007 of about 250 million connections and mobile coverage for 85 . India now has 49.75 million fixed subscribers and 100 million mobile users, for a total of about 150 million. That may seem like a large figure, but with a population of 1.08 billion, it translates to just 14 phones for every 100 people. And that number is skewed by the relative wealth of the cities while urban teledensity is around 31 percent; just 2 percent of the rural population has phone lines. With India's expanding middle class, demand for telephone services is growing beyond carriers' ability to keep up. The telecom ministry is initiating an ambitious project to release a total of about $45 \mathrm{MHz}$ of spectrum from the Department of Defence to augment necessary spectrum for $3 \mathrm{G}$ services.

Although details are not yet available, the cost has been estimated at about US\$225 million and the time frame is expected to be early 2010 . With respect to rural connectivity, the government's objective is to reach about 50 million rural connections, or one phone per three rural households, by 2007 and about 80 million rural connections, or one phone per two rural households, by 2010 .

\section{BROADBAND ACCESS ANYWHERE}

The two driving forces of modern Internet are broadband, and wireless. The systems based on Institute of Electrical and Electronics Engineers (IEEE) 802.16 standards combine the two, delivering high-speed broadband Internet access over a wireless connection. The systems based on latest IEEE 802.16e standard will help in achieving the goal of "Broadband Access Anywhere". [1]

\section{A. WiMAX Forum}

The WiMAX Forum is an industry-led, non-profit corporation formed to help, promote and certify the interoperability of broadband wireless products compliant with the IEEE 802.16 standards. The Forum's goal is to accelerate global deployments and grow the market for standards-based, interoperable, broadband wireless access solutions. The WiMAX Forum is working with member companies to develop standardized profiles and inter operable WiMAX products around specific spectrum bands. To date, there are over 368 member companies in the WiMAX Forum including, 136 service providers. The systems/CPEs based on IEEE 802.16 family of standards after certification for conformance and interoperability by WiMAX forum is called as WiMAX systems

\section{B. IEEE 802.16: Technology Overview}

IEEE 802.16 is a family of standards designed to address the needs for Wireless Metropolitan Area Networks 
(WMANs). There are currently two implementations being implemented for Broadband Wireless Access (BWA) systems: 802.16-2004 commonly known as 802.16d OFDM based for fixed applications and 802.16e OFDMA (orthogonal frequency division multiplexing access) for mobile applications.

(i) IEEE 802.16-2004 OFDM Based (Generally called as 16d): IEEE 802.16-2004 was released in June 2004 and contains a physical (PHY) and MAC layer specification for two key applications: The most common implementations at this time are 256 OFDM for bandwidths below $10 \mathrm{MHz}$.

(ii) The IEEE 802.16e standard was finalized in December, 2005 and released in February, 2006. IEEE 802.16e Standard envisages enhancements designed to add a new Physical (PHY) and Media Access Control (MAC) layer for mobile Broadband Wireless Access (BWA). This standard is known as $802.16 \mathrm{e}-2005$ OFDMA and has also been referred to as 802.16e or Mobile Worldwide Inter operable Microwave Access Systems (WiMAX).

The expectations from mobile application of WiMAX are cellular-like mobility with higher bandwidth and lower costs as compared to $3 \mathrm{G}$ cellular systems. The evolving $802.16 \mathrm{e}$ OFDMA based systems are initially focusing on licensed bands in the 2 to $4 \mathrm{GHz}$ range. The equipments have also been envisaged in the unlicensed $5 \mathrm{GHz}$ band. Leading global companies are making significant R\&D investments in $802.16 \mathrm{e}$ systems betting that it may become one of the key global standards for mobile broadband wireless access with end-to-end IP technology. [2,3]

\section{Spectrum for WiMAX [4]}

WiMAX frequency bands and profiles for Certification Initial plan:

(a) The frequency bands for the 802.16-2004 profiles: Profiles are a set of options of modulations, number of Fast Fourier Transforms (FFTs) etc. given in IEEE standard. The WiMAX Forum certification working groups have finalized the initia 1 certification profile for the first wave of WiMAX Forum Certified equipment (being called as Certification Wave 1 'CW1') as below in TABLE 1

\begin{tabular}{|c|l|l|}
\hline $\begin{array}{c}\text { Freq } \\
\text { Band(MHz) }\end{array}$ & $\begin{array}{l}\text { Duplexin } \\
\text { g }\end{array}$ & $\begin{array}{l}\text { Channelization(M } \\
\text { Hz) }\end{array}$ \\
\hline \multirow{3}{*}{$3400-3600$} & TDD & 3.5 and 7.0 \\
\cline { 2 - 3 } & FDD & 3.5 and 7.0 \\
\hline $5725-5850$ & TDD & 10 \\
\hline
\end{tabular}

TABLE I

FIRST WAVE” PROFILES

(b) The frequency bands for the $802.16 \mathrm{e}-2005$ profiles: The initial profile plan for certification against IEEE 802.16e 2005 is shown in TABLE 2 below:

\begin{tabular}{|c|c|c|}
\hline Freq Band(MHz) & Duplexing & $\begin{array}{l}\text { Channelization(M } \\
\text { Hz) }\end{array}$ \\
\hline \multirow[b]{2}{*}{$2500-2690$} & TDD & 5.0 and 5.5 \\
\hline & FDD & 5.0 and 5.5 \\
\hline
\end{tabular}

Note: Profiles are for PMP systems only and for 256 OFDM

\section{WiMAX frequency bands and profiles for Certification -} Current plan:

Recently WiMAX Forum collected data from the market and based on the survey, the tentative plan for certification against IEEE $802.16 \mathrm{e}-2005$ under consideration is as shown below in Fig 1 (Plan under consideration as draft in WiMAX Forum).Till date WiMAX forum have not adopted 3.3-3.4 $\mathrm{GHz}$ band in its recommended profiles or in its road map of up to 2007 (only recently in a draft plan it is included and not yet formally approved due to lack of available manufacturer's interest). This implies that protocol conformance testing and interoperability testing will be a key issue in $3.3-3.4 \mathrm{GHz}$ band.

\begin{tabular}{|l|l|l|l|l|l|}
\hline \multirow{2}{*}{ Certification Profiles } & \multicolumn{4}{|l|}{$\begin{array}{l}\text { Product Avalability } \\
\text { Sulumion }\end{array}$} & for Cetification \\
\cline { 2 - 6 } & Q406 & Q107 & Q207 & Q307 & Q407 \\
\hline $2.3-2.4 \mathrm{GHz}, 8.75 \mathrm{MHz}$ & $\mathrm{X} 1$ & & & $\mathrm{X} 2$ & \\
\hline $2.3-2.4 \mathrm{GHz}, 5 / 10 \mathrm{MHz}$ & & $\mathrm{X} 1$ & & $\mathrm{X} 2$ & \\
\hline $\begin{array}{l}2.305-2.320,2.345-2.360 \mathrm{GHz} \\
5 \mathrm{MHz}\end{array}$ & & & $\mathrm{X} 1$ & $\mathrm{X} 2$ & \\
\hline
\end{tabular}

Fig. 1. Plan Under consideration as draft in WiMAX Forum for IEEE 802.16e products

\section{KEY ISSUES}

\section{A. "Technology Neutral" or "16 d" or "16 e"}

Considering higher spectral efficiency, whether India is to adopt and deploy $802.16 \mathrm{~d}$ based systems at all or not or may allow up to a certain time period say December, 2006. After a time line say from 1st January 2007 only systems based on $802.16 \mathrm{e}$ were mandatory. The worldwide operators and administrations are tracking 802.16e developments. The method to enforce a policy needs consideration.

\section{B. Alignment of Spectrum}

How we will align our spectrum allocation to worldwide spectrum allocations. For this $2.5 \mathrm{GHz}$ band, $2.3 \mathrm{GHz}$ band and $700 \mathrm{MHz}$ band may be thought along with $3.3-3.4 \mathrm{GHz}$ 
and 3.4 - $3.6 \mathrm{GHz}$ for IEEE $802.16 \mathrm{e}-2005$ based systems. In U.S., $700 \mathrm{MHz}$ band were allocated in 2009 for which WiMAX society is also looking eagerly for possible deployment.

\section{FDD or TDD or Both}

The frequency plan adoption should be based on FDD or TDD. Worldwide trend is for TDD.

1) Band Partitioning: Whether FDD and TDD mixed allocation within a band can be done or band is to be partitioned for FDD allocation and TDD allocation to minimize mutual interference.

2) Three Sectors or Four Sectors: Typically three sector (three carriers or one carrier) and four sector (two carriers) working is possible. A three sector site may be deployed with different frequency carrier (total three carriers) in each sector or with same carrier in each sector (frequency reuse of 1 case). Whether three sectors and frequency reuse of one should be made mandatory or it may be left to the operators considering spectral efficiency issue.

\section{Full Mobility and VoIP}

Considering full mobility and VoIP application, there is a need to identify licensing and regulatory issues and to sort them out. India started its economic liberalization program in 1991. In 1994, the first step to India started its economic liberalization program in 1991. In 1994, the first step to opening the telecom market to privatization was taken. The first private sector wireline and cellular licenses were issued in 1995. From then on, Indian telecom has seen several milestones crossed and many missteps that provided valuable lessons.

The effective telecom tariff for domestic voice service has dropped from Rs 14 per minute (US\$0.3 at US\$1 = Rs 44.5) to about Rs 1 (US\$0.02) per minute in the last 10 years. The result is that the number of telephone connections (wireline and wireless lines) has doubled in the past two years, to about 150 million. The Ministry of Telecom has set a target for 2009 of about 350 million connections and mobile coverage for $85 \%$ of the countries geographical area, from about 30 India now has 59.75 million fixed subscribers and 125 million mobile users, for a total of about 200 million. That may seem like a large figure, but with a population of 1.18 billion, it translates t o just 14 phones for every 100 people. And that number is skewed by the relative wealth of the cities - while urban teledensity is around 31 percent, just 2 percent of the rural population has phone lines. With India's expanding middle class, demand for telephone services is growing beyond carriers' ability to keep up. The telecom ministry is initiating an ambitious project to release a total of about 45 $\mathrm{MHz}$ of spectrum from the Department of Defence to augment necessary spectrum for $3 \mathrm{G}$ services. Although details are not yet available, the cost has been estimated at about US $\$ 400$ million, and the time frame is expected to be early 2009. With respect to rural connectivity, the government's objective is to reach about 50 million rural connections, or one phone per three rural households, by 2009 and about 120 million rural connections, or one phone per two rural households, by 2010 .

\section{BROADBAND MARKET}

Broadband services were launched in India in 2007. ADSL services now cover 300 towns with a combined 1.5 million connections, while broadband wireless subscriber figures are still negligible. While low broadband penetration is a clear opportunity for BWA/WiMAX, the market take off will require sufficient spectrum, very low cost $\mathrm{CPE}$ and affordable end-to-end connectivity, including the computing platform. A country where broadband's average revenue per user (ARPU) is estimated at US\$8-10 requires very low equipment cost. In fact, Huawei is already delivering DSL modems at US\$13 to Indian operators. The Indian telecom sector operates in a volume-driven market. If the broadband market in India grows to meet the government's revised targets, it might spur one of the world's largest broadband wireless markets. For example, target broadband connections have been currently revised to 15 million subscribers by 2009 and 20 million by 2010. Quite likely the majority of these will be wireless broadband connections because of the poor wireline infrastructure in place.[1,5]

1) $B W A /$ WiMAX Regulation [6,7]: Enough operators are complaining about lack of adequate radio spectrum, that the government is considering the release of some of the spectrum held by the departments of Space and Defence. Currently, license holders in the 3.3-3.4 GHz band have on average, a spectrum of $2 \times 6 \mathrm{MHz}$ to deploy broadband services, even though an analysis shows that $20 \mathrm{MHz}$ is the minimum to support wide scale deployments and hence a profitable business case.

At the end of June 2006, the Telecom Regulatory Authority of India (TRAI) initiated a public consultation on "Allocation and pricing of spectrum for $3 \mathrm{G}$ services and broadband wireless access" including WiMAX. This consultation, in which the WiMAX Forum is keen to participate, and we know price has been finalized in mid June 2009. Further pressure on available bandwidth is coming from operators who require allocations of the 3G/UMTS spectrum. BWA/WiMAX technologies require specific frequency bands to be opened $\mathrm{u}$ $\mathrm{p}$ in the $3.5 \mathrm{GHz}$ band (an internationally approved standard), which is currently allocated to the Department of Space for INSAT downlink. Regulators and policy makers are deciding the best way to manage the spectrum.

2) BWA/WiMAX Activity [10] [8]: Bharti TeleVentures, Reliance, SIFY, BSNL and VSNL (Tata Group) have all acquired licenses in $3.3 \mathrm{GHz}$ range and are in various stages of trials. VSNL has announced Phase 1 pre-WiMAX deployment of Aperto gear in 60 locations, extending to 200 locations within the year. Although there is clearly insufficient spec trum to offer DSL-like service, several operators have 
indicated that there is still a huge market for 64 and $128 \mathrm{~kb} / \mathrm{s}$ connections, which should alleviate the lack of spectrum. Other active players include utilities and several branches of the Indian government. Intel is making significant progress in working closely with the Indian Government in bringing the latter's rural broadband goals to reality. The innovative "village entrepreneur" model, together with a net-enabled community info-kiosk, is an ideal way to reach the many who are not yet connected. While Motorola is strengthening its presence in the hinterlands through its extensive BWA projects for state governments, A lcatel has set up a joint venture with the C-Dot (the RD arm of the DoT) to focus on exclusive BWA/WiMAX solutions that are tailor made for India at price points the Indian consumer is comfortable paying.Current Market Structure in India is givenin Fig 2.

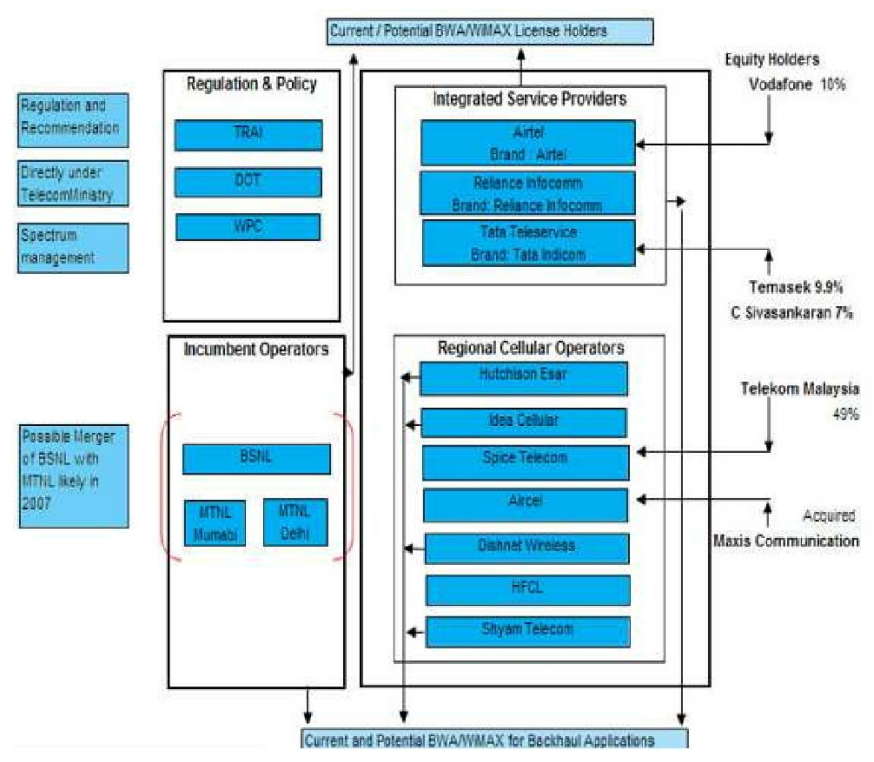

Fig. 2. Current Market Structure: India

3) Anticipated Developments: Several key events should influence the Indian BWA/WiMAX environment in the months ahead. While most operators have only conducted limited trials of vendor products, we expect larger deployments to begin in January 2009, provided that the needed additional spectrum is made available as envisioned. The mobile industry, already faced with a steep decrease in voice ARPU, is expanding its reach by offering voice services in rural areas and high-margin data services in urban areas in order try to increase revenues. Mobile TV, IPTV and other broadband applications are under trial at Reliance, Bharti and MTNL. The increased level of ecommerce activity - mainly through travel bookings, discount airfares, holiday destination packages, job hunting and matrimonial services - is creating a huge demand for always-on broadband services that is expected to take the current Internet user population to 150 million before 2009. Government-led initiatives with strong technology partners such as Intel, Motorola and Alcatel will trigger successful applications such as the Railtel cyber-cafe network along the entire rail route of the nation. Local technology-product companies with differentiated products engineered in India will have an opportunity to deploy in large domestic networks, learn from the experience and go global. Thus, they could form the first-generation Indian telecom product companies to address global markets. The mobilecontent industry in India is on the threshold of great change, as television, production houses and content aggregators are working frantically to define the new fronti er in the Indian content business. Mobile operators and ISPs that have strong alliances with content developers will be able to define the content-licensing model, which is at the heart of the broadband business. This will pose a new challenge for Indian service providers. Although the Indian broadband arena is emerging, it clearly offers huge potential for those that can demonstrate perseverance, patience and commitment. Market Forecasts [6][9] In 2009, the BWA equipment market opportunity was a mere US\$10 million, dominated by small deployments for backhaul applications to enterprises with outdoor equipment. However, we believe that with the upcoming spectrum opening, the certification o f new equipment and lower-cost CPEs, the annual 3.3 and $3.5 \mathrm{GHz}$ equipment opportunity will increase from US\$4 million in 2009 to US\$300 million in 2012. This report projects an accumulated 18 million BWA subscribers by 2012, counting both residential and business segments. WiMAX subscribers should represent two-thirds of this figure. Approximately $60 \%$ of the WiMAX subscribers will be mobile customers, who are predominately residential, while fixed WiMAX will continue to be driven by large corporations and, to a lesser extent, by SME customers. Methodology Assumptions [2] The research was conducted through two main channels:

4) Primary Sources: The survey took place from January to June 2009 and involved discussions with product managers, marketing executives, regulators, technologists and sales people at all organizational levels.

5) Secondary Sources: We always strive to provide our clients with a new and unique perspective of the industry

based on our own research. To ensure that we add value to the information already available to stakeholders in the industry, we reviewed most of the market research available on broadband wireless access in India, including:

- ITU Statistical Yearbook, 2008

- TheWorld BankDevelopmentIndicators, 2008

- Numerousarticles

- IndianISP Association

\section{CONCLUSION}

In the current scenario with respect to the country India. WiMAX subscriber base is expected to reach 19 million by 2012 and WiMAX equipment market value to top US\$600 million eventually following the auction of $2.3 \mathrm{GHz}$ and 
2.5GHz licenses in the first quarter of 2010. This report seeks to provide a comprehensive picture of WiMAX development in India, focusing on the three aspects of policy, industry, and market.

\section{FUTURE RESEARCH}

We know all over the world now in the condition to deploy the WiMAX or Korea, USA etc has been implemented successfully. But our country still in Dilemma we are still fighting for frequency band. In my view unfortunately this is beneficial for our country because we are in initial stage of $3 \mathrm{G}$ technology so cost is doesn't matter. We are in the really good condition to take the WiMAX technology. So we will give a proper and useful suggestion to govt of India so that we can able to deploy WiMAX in our country through this survey.

\section{REFERENCES}

[1] in http://wimax.com/search?SearchableText=India

[2] in http://en.wikipedia.org/wiki/WiMAX.

[3] Protiviti, "Wimax the quintessential answer to broadban $d$ in india," 2009.

[4] W. FORUM, in WiMAX Forum WiMAX Technology Interest survey and consultation regarding licences in the frequency bands 1900-1905 and 2500-2690 MHz WiMAX Forum Response, May 2007.

[5] R. M. Jeffrey G. Andrews, Arunabha Ghosh, in Fundamentals of WiMAX Understanding Broadband Wireless Networking, vol. 1, Jun 2010, pp. 1-478.

[6] R. K. Jha, in http://ezinearticles.com/?How-WiMAXWill-Deploy-inOur-Country-Indiaid $=4290465$.

[7] W. FORUM, "Wimax forum wimax technology forecast (200720 12)," in Survey on Indian market trends in WiMAX, 2008.

[8] B. included a report, "Current status and future develop ment of wimax in india: Policies, industry, and market."

[9] Maravedis, in India Broadband Wireless and WiMAX Market Analysis Forecasts 2007-2014 2nd Edition, Oct 2007.

[10] W. FORUM, in WiMAX Forum Industry Research Report, Review of April, 2009, April 2009 